\title{
Mudando o jogo: a relação da mente consigo mesma como chave para a beatitude
}

\author{
JONATHAN ALVES FERREIRA DE SOUSA *
}

\begin{abstract}
RESUMO A mudança de perspectiva proposta por Spinoza na metade da última parte de sua obra magna se mostra deveras interessante e suscita uma série de questionamentos. Nosso ponto aqui é tentar mostrar que nesta última parte da Ética demonstrada à maneira dos geômetras, Spinoza parece abandonar o conceito de paralelismo colocando em jogo não mais a mente em relação com corpo, o que foi feito em toda a Ética, mas agora, tomando a parte eterna da mente como sendo superior à parte temporal, sendo este o caminho principal para o indivíduo alcançar a beatitude. Mas porque a parte eterna da mente é superior a temporal? Quais são as implicações desta interpretação neste ponto crucial da Ética? Nossa proposta é sustentar que em toda a segunda metade da parte 5, que se inicia na proposição 21, Spinoza, fortalecerá a tese de que a ligação do indivíduo com as coisas deste mundo, perecíveis e mutáveis tem menos valor na busca da felicidade, liberdade, beatitude, do que a ligação com o que é eterno e imutável, que é Deus, em sua eternidade e amor. Beatitude e liberdade para Spinoza parecem fazer parte de uma estrutura de ações reflexivo-racionais. O conhecimento que o indivíduo tem de sua eternidade é um saber racional reflexivo, pois somente voltando-se para a sua própria alma de maneira racional é que pode saber que é eterno. Assim, o que tentaremos demonstrar é que a parte eterna da mente é superior a temporal porque somente através dela que o indivíduo pode ter um conhecimento racional de sua eternidade quando a partir disto, passa a saber que sabe que é eterno e livre. E neste processo de reflexão da mente consigo mesma é que se encontra a chave para a beatitude.
\end{abstract}

PALAVRAS-ChaVe Paralelismo; Eternidade; Essência; Liberdade

* Mestrando no Programa de Pós-Graduação em Lógica e Metafísica | PPGLM/IFCS Bolsista CAPES 


\section{INTRODUÇÃO}

A mudança de perspectiva proposta por Spinoza na metade da última parte de sua obra magna se mostra deveras interessante e suscita uma série de questionamentos. Nosso ponto aqui é tentar mostrar que nesta última parte da Ética demonstrada à maneira dos geômetras, Spinoza parece abandonar o conceito de paralelismo entre mente e corpo, colocando em questão não mais a mente em relação com corpo, o que foi feito em toda a Ética, mas agora, tomando a parte eterna da mente como sendo superior à parte temporal e, sendo este o caminho principal para o indivíduo alcançar a beatitude. Na relação da mente consigo mesma é que se encontra o caminho para a beatitude.

A beatitude para Spinoza, neste ponto, tem menos a ver com a vida presente ou com os "remédios para as afecções" ou com o que é perecível e mais a ver com a ligação do indivíduo com o que é eterno, infinito, e, por isso, pode-se dizer que a parte eterna da mente tem mais superioridade do que a parte temporal. Nos parece que Spinoza quer mostrar que esse corte no pensamento desenvolvido até a proposição XX da parte $\mathrm{V}$ da Ética é necessário para fazer com que o leitor entenda que o homem só é capaz de atingir a verdadeira felicidade enquanto estiver inserido na universalidade divina, como parte integrante de sua totalidade, capaz de compreender-se no todo de sua existência a partir de ideias adequadas.

O ponto de partida será o tema do paralelismo e algumas questões logo se apresentam. Como se dá a relação entre mente e corpo? A sua identidade é do tipo numérica ou mente e corpo são realmente distintos? A partir das teorias expostas por Della Rocca $^{1}$, Deleuze $^{2}$, Bennett ${ }^{3}$, entre outros comentadores, buscaremos elucidar qual

1 Della Rocca irá falar da mente e corpo como sendo numericamente idênticos. Não concordamos com sua abordagem, pois, nos parece que ele confunde a identidade existente entre a substância pensante e a substância extensa com a identidade dos modos.

2 Deleuze se valerá do conceito de representação ao qual nos parece mais adequado. Cf. E2p13. É evidente que a noção de representação não invalida a de identidade.

3 Bennett negará a identidade numérica proposta por Della Rocca, pois acredita que o mesmo confunde, assim como nós acreditamos, a identidade existente entre a substância pensante e a subs- 
tese faz mais sentido à luz dos textos spinozanos e como eles influenciam o posicionamento de uma relação mente x mente para que o indivíduo alcance a beatitude. O que tentaremos demonstrar por fim, é que a assimetria ${ }^{4}$ assumida entre mente e corpo irá desaparecer na segunda metade da parte V da Ética, quando Spinoza assume que o pensamento racional reflexivo, aquele que está presente na relação mente $\mathrm{x}$ mente e que passa a ser a chave para a beatitude.

Sobre o paralelismo, sustentaremos nossa abordagem a partir das teses de identidade e representação expostas por Della Rocca e Deleuze, respectivamente, e as objeções ou ratificações propostas por outros comentadores “clássicos” de Spinoza. Mas porque a parte eterna da mente é superior a temporal? Quais são as implicações desta interpretação neste ponto crucial da Ética? Nossa proposta é sustentar que em toda a segunda metade da parte V, que se inicia na proposição XXI, Spinoza, fortalecerá a tese de que a ligação do indivíduo ${ }^{5}$ com as coisas deste mundo, perecíveis e mutáveis tem menos valor na busca da felicidade, liberdade, beatitude, do que a ligação com o que é eterno e imutável, que é Deus, em sua eternidade e amor.

Na E5p39, Spinoza, dirá que “quem tem um corpo capaz de muitas coisas tem uma mente cuja maior parte é eterna". Na sequência desta proposição, o filósofo holandês parece demonstrar que há alguma relação entre o aumento das qualidades corporais que faz com que o corpo seja afetado menos pelos afetos maus com o consequente aumento de uma maior parte eterna da mente. Como pode haver essa relação se falamos aqui de uma parte da mente que é eterna em relação com aumento de qualidades corporais que se dá no tempo? Este posicionamento de Spinoza parece evidenciar a mudança de perspectiva apontada no final do escólio da $\mathrm{E}_{5} \mathrm{p} 20$, onde diz que passará a falar não mais do corpo com relação à mente, mas somente de uma parte da mente que não tem relação com o corpo, ou seja, a parte eterna da mente. A partir deste ponto é que tentaremos sustentar que a beatitude está ligada fundamentalmente a um posicionamento da mente com relação a si mesma e não com o corpo.

tância extensa com a identidade dos modos. Ele afirma que o caráter modal das coisas finitas é fundamental para o não colapso do sistema filosófico spinozano.

4 Esta assimetria é explicada pela capacidade de o Pensamento representar realidades distintas de si mesma.

5 De acordo com E2p21, indivíduo aqui é entendido como a unidade de uma ideia e de seu objeto. 
Esta relação da mente consigo mesma permeia toda a segunda metade da parte $\mathrm{V}$ da Ética onde Spinoza constantemente faz referências à parte eterna da mente como primordial para alcançar um conhecimento adequado de Deus e do mundo. Spinoza ainda diz claramente que a parte principal da mente é a parte eterna ${ }^{6}$, que a parte que permanece é mais perfeita que a outra que perece. ${ }^{7}$ Assim, consideramos suficientemente claro que a parte eterna da mente e sua relação com a parte temporal, nesta atitude racional reflexiva é primordial para alcançar a beatitude, mas que a parte eterna é superior à temporal, pois somente a partir dela que o indivíduo consegue se enxergar participante da eternidade divina. A mente que dura enquanto dura o corpo ${ }^{8}$, não é capaz de se perceber eterno justamente porque são configurações passageiras da extensão, das leis de movimento e repouso.

Nosso intento final é mostrar que, apesar de todas as recomendações anteriores, Spinoza, em seu projeto ético, evidenciará que na verdade o que importa realmente para alcançar a liberdade e felicidade não é o corpo e sim a alma, pois como buscaremos provar, a parte eterna da mente é mais importante que a parte temporal, e, por isso, a mudança de perspectiva na passagem das proposições XX e XXI tratará quase que exclusivamente, e digo quase, pois Spinoza retornará ao tema do corpo atual nas últimas proposições, da necessidade de pensar a relação da alma consigo mesma, pois somente na relação da mente consigo mesma é que o indivíduo alcançará a beatitude.

Por fim, e talvez ainda mais interessante é perceber que Spinoza retoma o tema do corpo presente na E5p39, mesmo tendo dito na transição da proposição XX para a XXI que não iria mais falar nada que tivesse relação com o corpo. A partir disto, indagamos de forma derradeira afim de tentar responder à questão principal neste trabalho, a saber, qual a relação de uma vida "segundo o ponto de vista da eternidade" com a vida prática dos indivíduos e como isso leva o homem a ser livre e encontrar a verdadeira felicidade? A consciência de nossa eternidade e seus desdobramentos traz algum conforto para a vida diária dos indivíduos? A consciência da relação da mente consigo mesma e da nossa eternidade nos repele ou nos insere ainda com mais força

6 E5p39esc.

7 E5p41cor.

8 E5p40c. 
nas relações mundanas e perecíveis que Spinoza busca em toda a segunda metade da parte $\mathrm{V}$ nos afastar?

A resposta a primeira e a segunda pergunta nos parece simples. Enxergar a vida sob o ponto de vista da eternidade, ou seja, de Deus, é enxergar a vida através da parte eterna da mente que se mostrará mais importante e fundamental para que o indivíduo perceba a partir de uma atitude racional reflexiva que a beatitude não está naquilo que é perecível ou passageiro ou nas coisas as quais são despertadas pelas paixões. A partir do entendimento da vida através do ponto de vista da eternidade, percebemos que participamos de algum modo desta mesma eternidade divina. Esta percepção deve trazer conforto, pois demonstra que o indivíduo conseguiu se afastar ao máximo das paixões que diminuem seu esforço em perseverar no seu ser e o quanto ele está mais próximo da beatitude ou da liberdade. A terceira pergunta proposta acima parece ser a de maior esforço para uma resposta. Ora, se estamos conscientes de nossa eternidade e vemos a vida através de um ato racional reflexivo e com isso nos aproximamos mais da beatitude, a resposta aqui se mostrará dúbia e novamente aparecerá uma assimetria, pois, ao mesmo tempo em que essa consciência nos repele da vida mundana, pois enxergamos as coisas sob o ponto de vista da eternidade, ela também nos insere com mais força nas relações cotidianas, afinal, sem a vida prática na duração, em ato, não poderia haver a possibilidade deste ato racional reflexivo que leva a beatitude.

A organização de nosso trabalho será dividido em três partes: 1) a da explicitação da teoria da união da mente com o corpo, mas comumente conhecida como a tese do paralelismo;2) a da compreensão da noção de eternidade e da parte eterna da mente; 3 ) a de uma possível resposta que tenha como base o ato racional reflexivo como ponto chave para a beatitude.

\section{UNIÃO MENTE X CORPO}

A relação mente e corpo é um tema recorrente em toda a filosofia. Spinoza, posicionando-se principalmente contra as teses clássicas de interação e união entre mente e corpo, contrapõe a elas a ideia radical de que “a ordem e a conexão das ideias é a mes- 
ma que a ordem e a conexão das coisas 9" e que "um modo da extensão e a ideia desse modo são uma só e mesma coisa, que se exprime, entretanto, de duas maneiras. ${ }^{10}$ ” No prefácio da parte 5 da Ética, Spinoza condena claramente Descartes por suas formulações acerca das teorias de união e interação mente e corpo e afirma: "não posso certamente surpreender-me o bastante de que um tal filósofo admita uma hipótese mais oculta que todas as qualidades ocultas. Que compreende ele, afinal, por união da mente e do corpo?”. Este “tal filósofo" era nada menos que Descartes. O que vemos na Ética é uma mudança profunda nos conceitos relacionados à ontologia humana com relação aos conceitos cartesianos e da tradição de maneira geral. Spinoza demonstrará que o homem é constituído de “corpo e mente, que são uma só e mesma coisa, o qual é concebido ora sob o atributo pensamento, ora sob o atributo extensão.” Grande será o debate entre os comentadores de Spinoza acerca das possibilidades de união e relação entre a mente e corpo e quais as suas implicações no sistema filosófico spinozano. Wolfson interpreta Spinoza a partir de Aristóteles e afirma que alma é a forma do corpo ${ }^{11}$. Jarrett interpreta que mente e corpo denotam uma coisa, embora concebidas de maneira diferente, em vez de duas coisas que são aspectos ou expressões de outra coisa. ${ }^{12}$ Bennett interpreta a relação mente x corpo como uma relação um-um, correlacionando itens mentais com os físicos. ${ }^{13}$ Della Rocca interpreta mente e corpo através de uma relação de identidade numérica. ${ }^{14}$

O que pretendo é analisar mais especificamente como se dá essa união entre mente e corpo, se através de uma relação de causalidade ou através do conceito de representação, se existe uma identidade numérica ou se será uma unidade modal funcional a melhor maneira de explicar a unidade da mente e do corpo. Como o paralelismo spinozano influencia ou é influenciado por esses conceitos também é parte importante de nosso trabalho.

$9 \quad$ E2p7.

10 E2p7s

11 WOLFSON, 1983, pp. 48.

12 JARRETT, 2007, pp. 75.

13 BENNETT, 1984, pp. 127.

14 DELLA ROCCA, 1993, pp. 183-213. 


\section{UNIÃO MENTE X CORPO EM DESCARTES}

Partiremos da teoria clássica do dualismo substancial cartesiano que afirma, a grosso modo: duas substâncias distintas e excludentes podem interagir entre $\mathrm{si}^{15}$. A maior crítica a essa formulação está na compreensão da afirmação de que duas coisas que nada têm de comum entre si, a saber, corpo e alma, estão unidas ${ }^{16}$. A princesa Elizabeth, com quem Descartes tem muitas correspondências, questiona a possibilidade de o que é imaterial, a alma, ter qualquer tipo de contato com o que é material, o corpo. Parece senso comum essa afirmação, apesar de percebermos que há algum tipo de relação entre a mente e o corpo, pois, sentimos que coisas que acontecem com o corpo nos afetam provocando reações e sentimentos na mente e, por outro lado, sentimos que a mente provoca ações diretas no corpo. Descartes acredita que o indivíduo é composto por alma, que nada mais é que uma substância pensante, que está unida a um corpo, que nada mais é que uma substância extensa. Assim, o homem para Descartes é composto por duas substâncias que nada têm de comum entre si. A relação posta em jogo por Descartes é a relação de causalidade. A tese da união e interação da alma e do corpo se dará através desta causalidade.

Na Sexta Meditação, Descartes introduz um conceito de união do corpo com a alma, que surge após o conhecimento prévio da existência do meu corpo; o argumento diz:

"A natureza me ensina, também, por esses sentimentos de dor, fome, sede, etc., que não meramente estou alojado em meu corpo, como um piloto em seu navio, mas que, além disso, lhe estou conjugado muito estreitamente e de tal modo confundido e misturado, que componho com ele um único todo.” ${ }^{17}$

Este argumento rejeita claramente, uma concepção platônica de que a alma é a essência do homem e o corpo um simples veículo e, por outro lado, não se identifica com o hilomorfismo aristotélico. Com base nas sensações, Descartes mostrará que o tipo de relação existente entre corpo e alma é uma relação de união substancial, ou seja, o fato de o homem ser uma única coisa, embora não seja uma "terceira” substância para

15 Não pretendemos, sobremaneira, esmiuçar a tese da união e interação entre mente, mais comumente chamado por Descartes de alma, e corpo neste trabalho. Nossa intenção é fazer apenas uma exposição panorâmica das teses cartesianas e contrapô-las às de Spinoza e de outros comentadores de Spinoza.

16 Correspondência entre Descartes e a Princesa Elisabete, 2017, pp. 198-199.

17 DESCARTES, Sexta Meditação, \$24. 
além de alma e corpo. Ora, os sentimentos confusos de fome, sede, etc., só podem estar em mim através de uma sensação mental, que é confusa, daquilo que ocorre em meu corpo. Logo, toda vez que sinto algo em meu corpo, uma comunicação acontece com o meu espírito, p.ex., quando me firo, eu (espírito) sinto dor. Da mesma maneira, quando escolho mover alguma parte de meu corpo, ocorre algo em meu espírito que é de alguma forma comunicado ao meu corpo, e então, eu movo meu braço.

Na prova da união da alma e do corpo por Descartes, é fundamental percebermos que ele supõe como aceitas duas provas anteriormente dadas, a da distinção real entre corpo e alma, ou seja, corpo e alma são duas substâncias realmente distintas e a prova da existência das coisas materiais. Partindo, assim, das sensações que tenho de coisas que me afetam, ele prova que o homem é constituído de corpo e alma, uma vez que, até então, o homem tudo o que ele sabia com certeza era que o homem é apenas uma alma. Descartes mostra que conheço que tenho uma alma mais estritamente unida a um corpo, pois sei da existência de outros corpos que me afetam, e sei também que só é possível que estes outros corpos me afetem porque tenho um corpo. Um problema que decorre diretamente desta teoria é: como explicar por que uma afecção de um corpo externo em mim é expressa em um ato da alma ou espírito? A resposta de Descartes será tentar mostrar que esta união entre corpo e alma é um tipo especial de união, onde a alma sofre certas modificações que a possibilitam ter atos como sentir, etc. Pelo fato de que aquilo que sinto é obscuro e confuso é que sei que a união da minha alma com meu corpo é especial, ou seja, uma mistura entre duas substâncias diferentes.

Uma outra maneira que Descartes escolhe para demonstrar a união do corpo e da alma é através do conceito de noções primitivas, conceito que está presente em sua correspondência a Elizabeth. ${ }^{18}$ Ele afirma que tanto as noções de corpo e alma, tomadas separadamente, quanto a do corpo e alma unidos ${ }^{19}$ são noções que estão em nós e que são como que originais, donde formamos todos os outros conhecimentos. Isto significa dizer que esta noção não pode ser explicada por nenhuma outra e que deve ser entendida por si. Para Descartes, o fato de haver certa confusão no entendimento

18 Correspondência entre Descartes e a Princesa Elisabete, 2017, pp. 196. Cf. também Princípios da Filosofia, Parte I, Artigo 48.

19 Ibid., pp. 196. "e enfim, da alma e do corpo juntos, temos a noção da união, da qual depende a da força que a alma tem de mover o corpo, e o corpo de agir sobre a alma causando seus sentimentos e paixões." 
acerca da união entre corpo e alma surge da confusão que fazemos ao tentar entender a interação alma x corpo através da interação corpo x corpo.

Aceitar o posicionamento cartesiano não resolve o problema da relação entre coisas de naturezas totalmente diferentes. A união é explicada segundo um dado experiencial, isto é, através das sensações. Por sua vez, a distinção é percebida pela razão. Cada noção, a da união e a da interação, é considerada como verdade, mas elas são conhecidas por caminhos diferentes. Ora, Descartes não parece estar preocupado com o problema da relação de coisas de naturezas diferentes ${ }^{20}$. Seu principal objetivo seria provar a distinção que há entre a alma e o corpo. Se tomarmos como auto evidente, assim como espera Descartes, a relação entre substâncias distintas, isto deveria ser aceito e compreendido por todos, pois seria um axioma sobre o qual não poderia haver dúvidas. Percebemos, porém, ao percorrer a história da filosofia, que este não é o caso, pois existe uma gama enorme de discussões sobre este problema da união entre mente e corpo.

Um que foi grande opositor das teses cartesianas, foi Baruch de Spinoza. Mesmo que aceite que haja uma íntima relação entre as partes que compõem o homem, Spinoza não poderia jamais aceitar a interação entre duas substâncias distintas e, de certa forma, excludentes. Assim, ele formula uma tese totalmente diferente para explicar como se dá essa relação entre mente e corpo. Uma tese que rejeita que haja qualquer tipo de relação causal entre aquilo que se dá no pensamento e aquilo que se dá na extensão. Esta tese ficou conhecida como a tese do paralelismo de Spinoza.

\section{O PARALELISMO SPINOZISTA}

A tese do paralelismo é exposta claramente na Ética:

"A ordem e a conexão das ideias é o mesmo que a ordem e a conexão das coisas”, e, “... a substância pensante e a substância extensa são uma só e mesma substância, compreendida ora sob um atributo, ora sob outro. Assim, também um modo da extensão e a ideia desse modo são uma só e mesma coisa, que se exprime, entretanto, de duas maneiras.” (E2p7s)

20 Correspondência entre Descartes e a Princesa Elisabete, 2017, pp. 196. 
Podemos perceber que Spinoza propõe haver uma relação de igualdade lógica entre a conexão das ideias e a conexão das coisas, ou propriamente, como diz no escólio, uma relação de igualdade lógica entre a potência de pensar de Deus e sua potência atual de agir. Como Deus é um ser infinitamente infinito e que conhece todas as coisas, daí se deriva que tudo o que se segue da potência de Deus é pensado por Deus, justamente por que tem como causa a sua essência. Isto diz respeito à representação das coisas finitas no intelecto infinito de Deus, pois elas, uma vez dadas, também deve ser dado o conjunto causal infinito de sua existência e a ideia infinita que as representa (E2p4). Outro ponto importante a se destacar é o uso, por Spinoza, da expressão uma e mesma coisa. É interessante como o filósofo usa esta expressão logo após relacionar a substância pensante e a substância extensa como uma só e mesma substância. Esta sequência parece demonstrar que a relação identitária existente entre as substâncias vale de igual maneira para os modos que dela derivam, sendo desta maneira também idênticos entre si.

Partindo da demonstração da proposição explicitada anteriormente, percebemos que Spinoza retoma o axioma 4 da parte 1 da Ética: “O conhecimento do efeito depende do conhecimento da causa e o envolve". Este axioma torna evidente que a relação de causa e efeito é fundamental no pensamento spinozano. É essa relação que explica o sentido do paralelismo, na medida em que é ela que permite passar da ordem do ser (conexão de causas e efeitos) para a ordem do conhecer (conexão do conhecimento das causas ao conhecimento dos efeitos). Ora, pela E1p15, sabemos que "tudo o que existe, existe em Deus, e sem Deus, nada pode existir nem ser concebido.” Portanto, “além de Deus, não pode existir nem ser concebida nenhuma substância”. Se Deus é causa de todas as coisas, ele também é causa dos modos existentes, mas apenas quando considerado sob o atributo do qual eles são modos, isto é, enquanto considerado como substância extensa, ele é causa dos modos da extensão e enquanto considerado como substância pensante, ele é causa dos modos de pensamento. Vale ressaltar que os modos finitos, enquanto considerados como tais, só serão causa de outro modo finito de mesmo atributo, ou seja, se for um modo da extensão, será causa de um modo finito da extensão, e se, ao contrário, for um modo do pensamento, ele será causa de um modo finito do pensamento. Isto porque, pela E2p6d, “... é por isso que os modos de cada atributo envolvem o conceito de seu próprio atributo e não o de um outro", não poderá haver relação causal entre diferentes atributos divinos 
e consequentemente da mesma maneira deve ocorrer com as modificações desses atributos. Um esquema poderia ser demonstrado da seguinte maneira para os modos da extensão (me):

$$
m e A \rightarrow \text { meB } \rightarrow \text { meC } \rightarrow \text { me... }
$$

e da mesma maneira para os modos do pensamento (mp):

$$
m p_{1} \rightarrow m p_{2} \rightarrow m p_{3} \rightarrow m p \ldots
$$

Temos aqui que meA é causa de meB que é causa de meC, e assim, ad infinitum. E da mesma forma acontece com os modos do pensamento, onde, mp1 é causa de mp2 que é causa de $m p 3$ até o infinito. Até este ponto não parece haver complicações ou debates acerca das relações de causa e efeito entre os modos. É de comum acordo que todos os comentadores afirmam que os modos não existem por si, mas que existem em outra coisa, por meio da qual também são concebidos. Na E2p7s, entretanto, Spinoza adiciona um fator importante e que irá mudar a maneira como se entende essas relações, que é a conjunção de um modo da extensão a um modo do pensamento pelo paralelismo. Como pode um modo da extensão e a ideia desse modo ser uma só e mesma coisa e se relacionar de alguma maneira se, como vimos, não pode haver relações causais entre diferentes atributos e suas modificações? Como mente e corpo, modificações de atributos realmente distintos entre si, podem ser um único ser? Uma chave para resolver essa questão seriam as passagens E1ax6, E2p11 e E2p13. Pela E1ax6, conclui-se que, para cada ideia verdadeira, deve concordar um ideato ou objeto, e, pelas E2p11 e E2p13, conclui-se que o que constitui o ser atual da mente é a ideia do corpo existente em ato. Portanto, podemos, de início, entender que, para cada modo do pensamento, haverá um modo da extensão com o qual ele concorde, o que se aplica de igual maneira a mente e corpo e poderia ser representado da seguinte maneira:

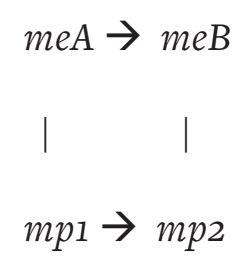

O que o esquema acima demonstra é o que está dito nas proposições e axiomas expostos anteriormente, a saber, que, para cada elo na cadeia causal, o efeito depende da sua causa e o envolve e que, para cada modo do pensamento ou para cada ideia, 
haverá algo correlato na extensão que os une, pelo paralelismo, e do qual a ideia é a sua representação em ato. Aqui há um perigo de erroneamente entender que a causa de meA seja a mesma de mpı. Isso jamais será possível e não é o que estou defendendo, visto que, como já exposto, atributos diferentes não podem compartilhar as mesmas causas. O que há de comum entre eles é o nexo causal que os torna verdadeiros. Explico melhor, se meA é a representação de $m p 1$, então, eles têm suas propriedades todas iguais, com exceção, respectivamente, da propriedade da extensão e da propriedade do pensamento. Logo, tudo o que estiver contido em $m p 1$ como força capaz de ser causa de $m p 2$, deve também estar contido em meA, uma vez que, meA é o correlato da representação $m p 1$. Voltando à passagem da E2p7s, percebemos que, se esta relação é verdadeira para os atributos divinos, também deveria ser para os modos singulares. Isto parece evidente, pois, na primeira parte do escólio, o filósofo atribui uma relação de identidade entre a substância pensante e a substância extensa e em seguida faz uma analogia com o modo da extensão e o modo do pensamento. Aqui irá residir boa parte dos conflitos entre os comentadores ${ }^{21}$. Nos parece claro que, em se tratando da substância pensante e a da substância extensa, que é uma só, mas expressa ora sob um atributo ora sob outro, e que vem a ser a tese do monismo ontológico, é o caso de afirmarmos que há sim uma identidade numérica. Como lemos, “... são uma só e mesma substância". Mas se a identidade existente aqui pode ser uma identidade numérica para a substância e se os modos são modificações dos atributos desta substância, não seria absurdo afirmar que há identidade numérica entre os modos, uma vez que o próprio escólio da proposição 7 parece demonstrar isto quando faz uma analogia que parte da substância e passa aos modos. O que irei sustentar é que o que há nos modos não é uma identidade do tipo numérica, ou seja, substancial, mas sim uma identidade de qualidades ${ }^{22}$, que exclui apenas, como apontado anteriormente, a igualdade entre as propriedades de pensamento e de extensão.

21 Analisaremos mais especificamente as divergências propostas por Della Rocca e Bennett, onde o primeiro defende a tese da identidade numérica dos modos como base para o paralelismo e o segundo vai negar essa mesma identidade numérica.

22 BENNETT, 1981, pp. 573-584, fala dos modos como adjetivos em substância subjacente. Assim, mente e corpo são modificações dos atributos como qualidades. O que Bennett tenta esclarecer é que a modalidade das coisas finitas é fundamental na filosofia spinozana. PINHEIRO, 2010, pp. 217-242, fala de uma explicação funcional para a identidade entre as coisas finitas. 
A confusão em afirmar que o mesmo estatuto ontológico dos atributos divinos se aplica aos modos, por E2p7e, parece inevitável. Mas um exame mais acurado tornará evidente que este não é o caso. Modos são nada mais do que afecções dos atributos divinos, como confirmamos pela E1p25c. Já pela E2p1o e seu corolário:

“À essência do homem não pertence o ser da substância, ou seja, a substância não constitui a forma do homem”; “Disso se segue que a essência do homem é constituída por modificações definidas dos atributos de Deus.”

A essência da substância é infinita e não carece de nada além de si para ser. Se os modos pudessem ter a mesma essência da substância, como indicaria uma leitura superficial do escólio da proposição 7 da parte 2, existiria mais de uma substância, o que é absurdo, como demonstrado na E1p5 e E1p14c1,2. Como modos finitos, eles precisam também de outras coisas finitas para existir, e não é por, em última análise, os modos serem modificações de Deus que eles terão o mesmo estatuto ontológico de Deus. O monismo spinozano, ou seja, a ideia de que só há uma substância, portanto, não fornece condições suficientes para afirmar que há uma identidade numérica entre os modos finitos, ou seja, entre mente e corpo. Mas como mente e corpo podem ser um único ser? Como eles se relacionam?

Como vimos, esta dúvida sobre a relação/união entre mente e corpo se dá, pois Spinoza usa uma analogia partindo da substância em direção aos modos quando usa a expressão uma só e mesma coisa. Devemos ressaltar que, Spinoza deixa claro na E2p8, a sua dificuldade em falar da substância e seus modos, "pois se trata de algo singular”. Contudo, é claro que não podemos simplesmente ignorar o uso desta expressão uma só e mesma coisa, mas querer que ela tenha a mesma força quando aplicada aos modos como quando aplicada à substância nos parece equivocado. Quando tomamos esta expressão aplicada à substância ou atributos de maneira forte, verificamos que, se atributos não têm nada de comum entre si, suas modificações não podem ser causa de outras coisas que estejam sob outro atributo. Se considerarmos a identidade numérica como válida, teremos que:

$$
\begin{aligned}
& m e A \rightarrow m e B \\
& m p 1 \rightarrow m p 2
\end{aligned}
$$

Se $\quad m e A=m p 1$ e $m e B=m p 2$

Então, $m e A \rightarrow m p 2$ e $m p 1 \rightarrow m e B$ 
Um problema que surge na conclusão do raciocínio acima é que Spinoza não pode aceitar a conclusão, devido à negação das relações causais entre os atributos mencionada anteriormente e que o filósofo demonstra em E2p6d e E3p2s, mas, no entanto, ele aceita a sentença de igualdade. Dizer, no entanto, que meA é igual a mpı não é suficiente para provar as diferenças modais que determinam igualdades e diferenças de todas as coisas, pois, se todos têm por causa Deus, como diferenciar mentes e corpos de si mesmos e de outros seres finitos?

\section{A PARTE ETERNA DA MENTE}

Apresentamos, nesta primeira parte, aquilo que convencionou-se chamar de "tese do paralelismo". Não obstante, sabemos pela E1p15 que todas as coisas estão contidas na ideia infinita de Deus ou nos seus atributos, o que significa que todas as coisas que estão contidas na ideia infinita de Deus só são eternas porque o ser que as contém é eterno.

Verificamos na afirmação acima, o ponto de partida para falarmos de uma parte da mente que é eterna e que não tem relação com o corpo. Este é o tema que Spinoza anunciará como sendo o principal tema da segunda parte da parte 5 da Ética. Ao final do escólio da proposição 20, o filósofo holandês afirma: “É, pois, agora, o momento de passar àquilo que se refere à duração da mente, considerada sem relação com o corpo". Spinoza, anuncia uma mudança que nos parece radical, pois, durante toda a Ética, percebemos o quanto ele está disposto a tratar do que pode o corpo e por quais vias este corpo pode padecer menos, e o quanto pode se alegrar mais. Agora, chegando ao final de seu projeto ético, Spinoza, aponta para uma direção que parece oposta a tudo o que já fora apresentado anteriormente. Ele aponta, portanto, que a culminância de sua Ética, ou seja, no que consiste a liberdade humana, não estará focada nas relações entre mente e corpo, mas sim em entender como a parte eterna da mente é capaz de levar o indivíduo a alcançar a beatitude. Desta maneira, uma passagem fundamental que precisamos nos deter é a da E5p23, que diz:

"A mente humana não pode ser inteiramente destruída com o corpo: dela permanece algo, que é eterno."

Durante anos a discussão sobre o conceito de eternidade da mente paira sobre a noção de eternidade como atemporalidade, isto é, sem relação com a duração em contraste com a noção de eternidade como sempiternidade. A definição de eternidade 
estabelecida por Spinoza possibilita entendermos que uma existência eterna pode ser de duas maneiras, a saber: 1) a partir de sua própria essência eterna; 2) a partir da sua causa eterna. Desta maneira, temos a partir da E1D8 que a existência de uma coisa pode ser eterna em virtude de ser sequência necessária apenas da definição da própria coisa. Aqui falamos de uma eternidade imediata, exclusiva de Deus; ao passo que podemos também falar em uma existência eterna mediata que se aplica aos modos e que é consequência necessária apenas da definição de uma outra coisa. Assim, respondemos de maneira satisfatória que eternidade é a própria existência de uma coisa, ora em virtude apenas da definição de si próprio, ora em virtude apenas da definição de sua causa própria, de tal maneira que essa eternidade é aplicada de tal forma à substância, ou seja, Deus, e a seus modos tanto infinitos como finitos. A substância e seus atributos são eternos por si e os modos, por sua vez, têm ao menos algo de eterno.

Na segunda seção da parte 5, Spinoza apresenta sua teoria da eternidade de uma parte da mente humana ${ }^{23}$. Sua centralidade está posta em 3 pontos cruciais, a saber ${ }^{24}$ :

Há em Deus uma ideia da essência formal de cada corpo humano.

Uma ideia da essência formal do corpo humano permanece após a destruição deste mesmo corpo, e por esta razão há uma parte da mente humana que é eterna.

Quanto mais sábio e mais conhecimento tiver das causas, maior é a parte da mente que é eterna.

Garrett afirma ${ }^{25}$ que para cada um destes 3 pontos, há duas maneiras diferentes de respondê-los as quais parecem inconsistentes com o resto da filosofia spinozana e que a chave para resolver essas aparentes inconsistências é entendermos a teoria spinozana das essências formais. Matson afirma, em concordância, que a "demonstração da eternidade da mente depende da noção do que é a essência do corpo humano" ${ }^{26}$. Ao fazer a passagem da primeira para a segunda seção no escólio da E5p2o, Spinoza

23 Curley, falando sobre esta parte diz: “... eu ainda não sinto que entendi esta parte da Ética adequadamente...” Cf. CURLEY, 1988, pp. 84. Bennett vai mais longe e indaga: "Por que Spinoza escreve isso?” e mais, “... isso é perigoso: isto é lixo que faz com que os outros escrevam lixo.” Cf. BENNETT, 1984, pp. 357 e 374.

24 GARRETT, 2010, pp. 284.

25 Ibid. 2010, pp. 284.

26 MATSON, 1990, pp. 85. 
anuncia que irá passar agora àquilo que "se refere à duração da mente sem relação com o corpo."

Nas proposições que se seguem, da E5p21 até a E5p32, ele irá fornecer uma complexa teoria da eternidade da mente. Um dos problemas clássicos que se apresentam nesta parte, é o já exposto problema da eternidade sendo confundida com sempiternidade. Outro problema fundamental é o do conceito de essência formal e existência atual do corpo humano ao qual nos deteremos mais especificamente. Um terceiro ponto derivado desta parte da Ética é o da imortalidade da alma ${ }^{27}$.

A distinção entre os conceitos de essência formal e de existência atual do corpo humano surgem já nas primeiras proposições desta segunda seção. As quais se seguem:

“A mente não pode imaginar nada, nem se recordar das coisas passadas, senão enquanto dura o corpo." (E5p21)

"A mente não exprime a existência atual do seu corpo, nem tampouco concebe como atuais as afecções do corpo, senão enquanto dura o corpo (pelo corol. da prop. 8 da P. 2) e, consequentemente (pela prop. 26 da P. 2), não concebe nenhum corpo como existente em ato senão enquanto dura seu próprio corpo. Logo, não pode imaginar nada (veja-se a def. de imaginação no esc. da prop. 17 da P. 2), nem se recordar das coisas passadas, senão enquanto dura o corpo (veja-se a def. de memória no esc. da prop. 18 da P.2). C. Q. D" (E5p21d)

"Em Deus, necessariamente existe, entretanto, uma ideia que exprime a essência deste ou daquele corpo humano sob a perspectiva da eternidade." (E5p22)

"Deus é causa não apenas da existência deste ou daquele corpo humano, mas também da sua essência (pela prop. 25 da P. 1), a qual deve, por isso, ser necessariamente concebida, em virtude de uma certa necessidade eterna (pela prop. 16 da P. 1), por meio da própria essência de Deus (pelo ax. 4 da P, 1). Este conceito [da essência deste ou daquele corpo humano] deve, portanto, necessariamente existir em Deus (pela prop. 3 da P. 2). C. Q. D.” (E5p22d)

Estas proposições são fundamentais para entendermos que o termo essência se refere à essência formal das coisas singulares e que este difere e não pressupõe ou im-

27 Nos deteremos mais especificamente sobre de que maneira é impactado na sua maneira de viver, o indivíduo que sabe que é imortal ou que sabe que não é imortal. Para uma compreensão a favor da imortalidade da alma, cf. Donagan, 1973, pp. 241-258. Para uma defesa contra a imortalidade da alma, cf. Nadler, 2002, pp. 224-244. 
plica a existência atual das coisas singulares. Na forma geométrica e dedutiva das proposições da Ética, a demonstração da proposição 21 acima exposta, bem como o da proposição 23 da qual falaremos mais adiante, aponta para o corolário da E2p8 que é uma proposição que diz respeito às essências formais das coisas singulares que não existem. Ora, o corolário desta mesma proposição dá o contraste entre as coisas singulares que não existem, "a não ser enquanto estão compreendidas nos atributos de Deus" 28 , e as coisas singulares que existem, "não apenas enquanto estão compreendidas nos atributos de Deus, mas também enquanto se diz que duram, as suas ideias envolverão também a existência, razão pela qual se diz que elas duram.” 29 Outrossim, "coisas singulares" são coisas finitas e têm existência determinada como definido através da E2D7. Não podemos deixar de salientar, sobremaneira, que toda coisa singular é um modo de Deus, ou seja, a essência e existência das coisas singulares têm Deus como causa ${ }^{30}$.

Spinoza aponta diretamente para a E2p8, pois esta proposição irá examinar a relação entre essência e existência. Como pelo paralelismo entendemos que cada corpo tem um ideia que lhe corresponde e vice-versa, e se um ser singular é um composto entre uma ideia e um corpo que lhe é sua representação, como falar de ideias de coisas não existentes em um âmbito que comporta, teoricamente, somente ideias que existem enquanto o corpo que lhe é correspondente existe?

Esta não é uma proposição simples e fácil de se interpretar. O próprio Spinoza faz um aviso ao seu leitor no início do escólio de que o exemplo que ele dará é inadequado, pois ele falará de algo singular. Este escólio irá comparar as coisas singulares não existentes, cujas essências estão contidas nos atributos de Deus a retângulos não traçados no círculo, mas que existem potencialmente no círculo, enquanto este dura. Desta maneira, Spinoza faz uma ligação entre a essência formal das coisas singulares à possiblidade não realizada da existência das coisas singulares. Por outro lado, ele deixa claro, no corolário desta mesma proposição, que a existência atual das coisas singulares está também compreendida nos atributos Deus, "mas também enquanto

$28 \mathrm{E} 2 \mathrm{p} 8 \mathrm{c}$

29 Ibid.

30 Cf. E1p25c 
se diz que duram, as suas ideias envolverão também a existência, razão pela qual se diz que elas duram" ${ }^{1}$.

Temos um duplo aspecto a ser explorado, o da existência em ato das coisas singulares e o da existência “em potência” das coisas singulares. A existência em potência, assim como a existência de seres singulares não existentes é verdadeira pois sua essência está contida e é derivada diretamente dos atributos de Deus. Sendo diretamente derivada dos atributos de Deus, ela é eterna. A existência em ato, por sua vez, pode ser de dois tipos ${ }^{32}$, temporal, que possui relação com a duração e é dada pelo nexo infinito de coisas singulares existentes ou eterna, não possuindo relação com a duração e consequentemente não tendo sua causa ou determinação em uma outra coisa singular. Deus é o único ente ao qual sua essência é suficiente para sua existência, pois tanto sua essência quanto sua existência são constituídas por seus próprios atributos. ${ }^{33}$

Ora ao inserir o tema da possibilidade, um problema emerge claramente, a saber, o do necessitarismo estrito de Spinoza ${ }^{34}$. Em suma a tese do necessitarismo diz que tudo o que é possível é atual e tudo o que é atual é necessário ${ }^{35}$. A questão aqui é como compatibilizar a teses apresentadas na E5p21, E5p21d, E5p22, Ep22d, com o necessitarismo ao qual estas mesmas proposições apontam? Para que o necessitarismo possa ser verdadeiro, não pode haver genuinamente essências formais não atualizadas. Ora, pela E1p25, Deus é causa eficiente das existências e das essências das coisas como já vimos. Uma essência cuja existência é meramente possível não precisa ter uma causa, pois não é uma realidade em ato. Para responder a este ponto, precisamos entender que as essências dadas não são independentes da potência causal de Deus, mas sim, que elas são necessárias por sua causa, Deus, no sentido que serão instanciadas necessariamente em algum momento do tempo. Assim, elas não são apenas possi-

31 E2p8c.

32 PINHEIRO, 2010, pp. 227.

33 Cf. E1p20

34 Pinheiro afirmará que o uso de uma noção de potência ou possibilidade feita por Spinoza “só tem se sentido, pois, referindo as coisas temporais às coisas eternas”. PINHEIRO, 2010, pp. 229.

35 Cf. E1p16; E1p29; E1p33; E1p35d. Em suas Considerações Sobre o Necessitarismo de Espinosa, Gleizer demonstra de maneira assertiva o caráter radical do necessitarismo spinozano, em contraste a um necessitarismo moderado apresentado por Curley. Cf. GLEIZER, 2003, pp. 59-87. Este necessitarismo de aspecto forte é o que adotamos aqui. 
bilidades lógicas, mas realidades necessárias que necessariamente existiram, existe ou existirão. Se as essências são mais do que meras possibilidades lógicas, sendo, portanto, uma realidade que tem a propriedade de necessariamente existir em algum momento, logo, elas devem ter uma causa eficiente, a saber, Deus. Desta maneira, as essências formais das coisas singulares devem ser modos de Deus.

Concluímos deste modo pela afirmação da E2p8 que as essências formais estão contidas nos atributos de Deus e por sua correspondência na E5p22 onde constatamos que a ideia da essência do corpo humano existe necessariamente em Deus. Isto é ainda mais evidente pela E1D5, onde Spinoza estabelece que um modo é afecção da substância. Um modo de Deus pode ser de dois tipos: 1) infinito e eterno, que se segue de Deus diretamente ou por outros modos infinitos; ou 2) finito e determinado em sua existência, que se seguem também de Deus, mas enquanto este é modificado ou afetado por um outro modo finito. ${ }^{36}$ Outrossim, se as essências formais das coisas singulares são modos de Deus, elas não parecem ser modos finitos, pois possuem sua própria existência contida nos atributos de Deus. O escólio da E5p23 parece confirmar o status modal infinito ao dizer que "Essa ideia que exprime a essência do corpo sob a perspectiva da eternidade é, como dissemos, um modo definido do pensar, que pertence à essência da mente e que é necessariamente eterno."

É possível inferir, a partir desta análise, que a essência formal de uma coisa singular não pode ser idêntica à coisa singular em si, pois um coisa singular em si é um modo finito cuja existência é finita e determinada, como atesta a E2D7, e tem sua essência formal como um modo infinito, que por sua vez, de alguma maneira, sustenta a atualidade das próprias coisas singulares em si. A partir deste ponto, podemos afirmar que a essência formal das coisas singulares deve ser um aspecto de um atributo de Deus que é capaz de sustentar a existência atual das coisas singulares, independentemente do nexo finito causal que as determinará a existir em ato ${ }^{37}$. Apesar de a existência das

36 E1p28d diz: “Tudo que é determinado a existir e a operar é assim determinado por Deus (pela prop. 26 e pelo corol. da prop. 24). Ora, o que é finito e tem existência determinada não pode ter sido produzido pela natureza absoluta de um atributo de Deus, pois tudo o que se segue da natureza absoluta de um atributo de Deus é infinito e eterno (pela prop. 21 ); [...] Deve, portanto, ter se seguido ou de Deus ou de um atributo seu, isto é, deve ter sido determinado a existir e a operar ou por Deus ou por um atributo seu, enquanto modificado por uma modificação que é finita e tem uma existência determinada."

37 É a instanciação da essência formal que produz a própria coisa singular existente em ato. 
coisas singulares se darem em uma duração limita, elas possuem uma essência formal derivada diretamente de um aspecto de um atributo divino que torna esta mesma essência eterna e ilimitada, assim como o seu atributo do qual é causa.

\section{O ATO RACIONAL REFLEXIVO COMO CHAVE PARA A BEATITUDE}

A mudança de perspectiva proposta por Spinoza na metade da última parte de sua obra magna se mostra deveras interessante e suscita uma série de questionamentos. Nosso ponto aqui é tentar mostrar que nesta última parte da Ética, Spinoza parece abandonar o conceito de paralelismo colocando em jogo não mais a mente em relação com corpo, que foi feito em toda a Ética, mas agora, tomando a parte eterna da mente como sendo superior à parte temporal, sendo este o caminho principal para o indivíduo alcançar a beatitude.

A beatitude para Spinoza, neste ponto, tem menos a ver com a vida presente ou com os "remédios para as afecções" ou com o que é perecível e mais a ver com a ligação do indivíduo com o que é eterno, infinito, e, por isso, a parte eterna da mente tem mais superioridade do que a parte temporal ${ }^{38}$. Uma vez que livre é o indivíduo que tem a capacidade de conhecer adequadamente a causa das coisas pela qual é afetado, e assim, agir ativamente aumentando o seu esforço de perseverar no seu ser, fica evidente que o conhecimento de uma parte da mente que é eterna é fundamental e lhe confere um status diferenciado em relação a parte da mente que perece juntamente com o corpo. A parte eterna, o intelecto ${ }^{39}$, que conhece as coisas pelas vias do $2^{\mathrm{o}}$ e $3^{\mathrm{o}}$ gêneros do conhecimento, é o caminho principal para a beatitude, pois, através dele que o indivíduo conhece as causas daquelas coisas que o afetam. Já a parte que perece juntamente com o corpo, conhece as coisas pela imaginação, ou seja, pelo $1^{\circ}$ gênero do conhecimento, conhecimento este confuso e inadequado.

Nosso intento foi mostrar que, apesar de todas as recomendações anteriores, Spinoza, em seu projeto ético, evidenciará que na verdade o que importa realmente para alcançar a liberdade e felicidade não é o corpo e sim a alma, pois a parte eterna da mente é mais importante que a parte temporal, e, por isso, a mudança de perspectiva na passagem das proposições 20 e 21 tratará quase que exclusivamente, e digo quase,

38 Esta afirmação será dita claramente por Spinoza na E5p40c e E5p4Os.

39 E5p40c. 
pois Spinoza retornará ao tema do corpo atual nas últimas proposições, da necessidade de pensar a relação da alma consigo mesma, pois somente nesta relação da mente consigo mesma é que o indivíduo alcançará a beatitude.

\section{REFERÊNCIAS BIBLIOGRÁFICAS}

ALLISON, H. E. “The Eternity of Mind: Comments on Matson on Spinoza”. In: Spinoza: issues and directions: the proceedings of the Chicago Spinoza Conference/edited by Edwin Curley and Pierre-François Moreau, 1990, pp. 96-101.

AQUILA, R. E. The Identity of Thought and Object in Spinoza. Project Muse. Scholarly journals online.

BARTUSCHAT, Wolfgang - Espinosa. Tradução de Beatriz Avila Vasconcelos. Porto Alegre: Artmed, 2010.

BENNETT, Jonathan - A Study of Spinoza`s Ethics. Hackett Publishing Company, 1984.

BRUNSCHVICG, Léon. "Spinoza: filosofia e teologia”. In: Estudos sobre Spinoza. Organizado por Cézar Benjamin. Rio de Janeiro: Contraponto, 2014.

CHAUÍ, Marilena - “Paixão, ação e liberdade em Espinosa”. In: Jornal Folha de São Paulo, Caderno MAIS!, 22 de agosto de 2000.

CURLEY, Edwin. Behind the Geometrical Method: A Reading of Spinoza's Ethics. Princeton. Princeton University Press, 1988.

DANIELS, C. B. "Spinoza on the mind-body problem: two questions". In: Mind, New Series, Vol. 85, $n^{0}$ 340, (Oct., 1976), pp. 542-558.

DELEUZE, Gilles. Espinosa e o Problema da Expressão.

DELLA ROCCA, Michael - Representation and the mind-body problem in Spinoza. Nova York: Oxford University Press, 1996.

_. "Spinoza`s Argument for the Identity Theory". In: The Philosophical Review, Vol. 102, $N^{\circ} 2$ (Abril de 1993), pp. 183-213. 
«Causation and Identity in Spinoza». In : «History of Philosophy Quarterly, Vol. 8, $N^{\circ} 3$, Julho de 1991.

DESCARTES, René - Meditações Metafísicas. Tradução de Maria Ermantina de Almeida Prado Galvão. São Paulo: Editora WMF Martins Fontes, 2011.

Meditações Metafísicas. Tradução de J. Guinsburg e Bento Prado Júnior. Coleção Os Pensadores. São Pulo: Editora Abril, 1973.

ESPINOSA, Baruch de - Ética demonstrada à maneira dos gêometras. Tradução de Joaquim de Carvalho (Parte I), Joaquim Ferreira Gomes (Parte II e III) e Antônio Simões (Parte IV e V). Coleção Os Pensadores. São Paulo: Editora Abril, 1973.

. Tratado da correção do intelecto. Tradução de carlos Lopes de Mattos. Coleção Os Pensadores. São Paulo: Editora Abril, 1973.

GARRETT, Don. "Spinoza on the Essence of the Human Body and the Part of the Mind That Is Eternal”. In: The Cambridge companion to Spinoza's Ethics / edited by Olli Koistinen. 2009, pp. 284-302.

GLEIZER, M. A. “Considerações sobre a definição de eternidade na Ética de Espinosa”. In: Cad. Hist. Fil. Ci., Campinas, Série 3, v. 19, n. 1, p.37-60, jan.-jun. 2009.

KOISTINEN, Olli; BIRO, John. Metaphysical Themes. Oxford University Press. 2002.

LAERKE, Mogens. "Spinoza on the Eternity of the Mind”. In: Dialogue 55 (2016), 265286.

PARCHMENT, Steven. “The Mind's Eternity in Spinoza's Ethics”. In: Journal of the History of Philosophy, Volume 38, Number 3, July 2000, pp.349-382

PINHEIRO, Ulysses. “A heresia oculta de Espinosa. Meditações sobre a morte na Ética”. In: Revista de Filosofia Analytica, Vol. 14, $N^{0} 1$ (2010), pp. 217-242.

RIZK, Hadi. Compreender Spinoza. Tradução de Jaime A. Clasen. Petrópolis: Editora Vozes, 2006.

ROCHA, Ethel Menezes - “Observações sobre a Sexta Meditação de Descartes”. In: Cad. Hist. Fil. Ci., Campinas, Série 3, Vol.16 (Jan-Jun de 2006), $N^{0} 1$, p.127-144.

WOLFSON, Harry Austryn. The philosophy of Spinoza. Harvard Univertity Press, 1934. 